\title{
Ponsonomonoser
}

2019, vol. 82, 17-23

http://dx.doi.org/10.12657/denbio.082.003

\author{
Tomasz Ozyhar, Giovanni Mughini, Maurizio Marchi*
}

\section{Influence of biostimulant application in containerized Eucalyptus globulus Labill. seedlings after transplanting}

Received: 10 October 2019; Accepted: 17 December 2019

\begin{abstract}
The use of biostimulants (amino acid containing protein hydrolysate) in forestry field has received much less attention so far than in agriculture. Promising evidences were reported in literature with useful application for nursery activities, stimulating early growth and reducing transplanting stress. This study investigates the potential benefits induced by an amino acid-based animal-derived protein hydrolysate biostimulant (Siapton ${ }^{\circledR}$ by Isagro) in containerized Eucalyptus globulus seedlings following transplanting. Foliar and soil drench applications were applied using two different concentrations each $\left(2.5 \mathrm{ml} .1^{-1}\right.$ and $5.0 \mathrm{ml} . \mathrm{l}^{-1}$ for foliar, $10 \mathrm{ml} . \mathrm{l}^{-1}$ and $20 \mathrm{ml} .1^{-1}$ for soil). Measures on seedling height, apical shot formation, total aboveground (dry weight of leaves and stem) and belowground biomass (dry weight of roots) 120 days after transplanting were made to quantify the effect on growth. The contrasts analysis on results revealed a positive effect of the biostimulant on many of the measured parameters, especially with foliar application using the lowest concentration $\left(2.5 \mathrm{ml} . \mathrm{l}^{-1}\right)$. The foliar application was overall suggested as more efficient than soil drench also allowing lower inputs (i.e. biostimulant quantity). The main consequence of the treatment was an increased biomass allocation in the stem (above ground biomass) due to a stimulated leaves production which might suggest an increased photosynthetic activity and growth. Conversely no influence was detectable on total height of seedlings neither on the collar diameter. The biostimulant treatment on containerized Eucalyptus globulus positively influenced some features of seedlings' growth after transplanting and the use of biostimulant with foliar application during the hardening phase in the nursery, appears to be a promising technique to potentially improve seedling growth after transplanting. An interesting impact from application of biostimulant on biomass accumulation following transplanting was here demonstrated. Anyway, further research to verify the results on different tree species as well as under open field conditions is envisioned.
\end{abstract}

Keywords: foliar treatment, forest nursery, soil drench, reforestation, forest ecology

Addresses: T. Ozyhar, Omya International AG, Baslerstrasse 42, CH-4665 Oftringen, Switzerland G. Mughini, CREA - Research Centre for Forestry and Wood, I-00166 Rome, Italy

M. Marchi, CNR - Institute of Biosciences and BioResources (IBBR), Florence division. Via Madonna del Piano 10, I-50019, Sesto Fiorentino (Florence), Italy, e-mail: maurizio.marchi@cnr.it

*corresponding author

\section{Introduction}

The use of external inputs such as mechanical site preparation, irrigation and fertilization is considered as crucial for the successful cultivation in agricultural systems and with and increasing interest in planted forests and in the forestry field (Coyle \& Coleman, 2005; Hall \& Richards, 2013; Perry et al., 2009; 
Wagner et al., 2006; Wang \& Xing, 2017). The use of substances referred to as "biostimulants" has been proposed in literature as an alternative and sustainable solution to increase productivity (Le Mire et al., 2016; de Pascale et al., 2017), driven by environmental concerns and the efforts to reduce the application amount of conventional fertilizers. Biostimulants are mainly used in nursery activities to stimulate seedlings growth as a mixture of polypeptides, oligopeptides and amino acids, directly applied to the rooting system by soil drench or via foliar application (Colla et al., 2017). Their main impact is on the absorption metabolism of carbon and nitrogen like auxin and gibberellins, with a modulation of plant molecules and physiological processes (Colla et al., 2017). Positive effects associated with the use of biostimulants range from improved fruit set and retention (Filiti et al., 1986), smaller sensitivity to abiotic stresses including salinity (Mladenova et al., 1998; Lucini et al., 2015), resilience to drought and extreme temperature conditions (Kaufmann et al., 2007; Xu \& Leskovar, 2015), heavy metals stockings (Zhu et al., 2006), as well as the ability to increase the absorption and use of nutrients (Halpern et al., 2015).

The ability to minimize the effects of abiotic stresses by application of biostimulants have been often discussed in literature and in addition to the increased yield (Caradonia et al., 2019; Yakhin et al., 2017) but their use in forestry has received much less attention so far than in agriculture. However promising results were achieved so far; according to Fraser and Percival (2003), application of biostimulants during transplanting phases for Fagus sylvatica L., Quercus rubra L. and Betula pendula Roth can improve seedlings vigor. A positive effect of biostimulants have been also demonstrated in terms of growth and development of the rooting system after transplanting in open field for Betula pendula and Sorbus aucuparia L. and especially when applied together with hydrogels (Barnes \& Percival, 2006). Anyway, poor results were achieved too with foliar and soil application not significantly improving the growth of Eucalyptus maidenii F. Muell. and E. globulus Labill. ssp globulus species even if combined with fertilization (Barboza Frioni, 2013; Brocco Silva et al., 2015; Moroy Rodriguez \& Sanchez Giménez, 2017). Further, biostimulants failed to enhance drought tolerance of Quercus ilex, Ilex aquifolium, Sorbus aucuparia, Fagus sylvatica, and Betula Papyrifera (Banks \& Percival, 2014; Richardson et al., 2004).

Overall, the issue of the real effect of biostimulants on forest tree species is currently under investigation with many research gaps to be filled. The physiological mechanisms regulating the action of the plant- and animal-derived protein hydrolysates on plants is still partially unknown (du Jardin, 2015; Yakhin et al., 2017). The selection of a suitable biostimulant and the appropriate concentration (i.e. dosage) has also often been mentioned as the most relevant factor but the conflicting results underlined the need for further research on their potential to enhance stress resistance and increase production also in forestry systems. In this framework the goal of the present study is to evaluate the influence of an amino acid-based animal-derived protein hydrolysate on growth of containerized Eucalyptus globulus seedlings after transplanting. The effect of the application of the biostimulant with different treatments (foliar versus soil drench application) was determined collecting a set of dimensional parameters (e.g. seedling height, number apical shots, allocated biomass, etc.) on seedlings 120 days after transplanting.

\section{Material and methods}

\section{Experimental design and biostimulant application}

The study was carried out in a greenhouse on $E$. globulus ssp globulus seedlings, coming from the "Ovile farm" in Italy $\left(41^{\circ} 54^{\prime} 40.7 " \mathrm{~N}, 12^{\circ} 21^{\prime} 50.1 " \mathrm{E}\right)$. The sowing took place in the first half of March and seedlings were transplanted into 60-hole plastic honeycomb containers one month later, with a volume of soil of about $260 \mathrm{cc}$ each. A commercial soil substrate, based on Irish and Baltic peat with agri-perlite and $\mathrm{pH} 6.0$ (Vigor Plant® SER CA V7P) was used and then, the biostimulant was applied during the hardening phase. The tested biostimulant was an amino acid-based animal-derived protein hydrolysate $(\mathrm{PH})$ sold under commercial name of Siapton ${ }^{\circledR}$ by Isagro whose chemical composition of the concentrated formulation is described in Mladenova et al. (1998). Two different application methods (foliar application and soil drench) were tested using different concentrations (Table 1). Four treatments were studied in total and applied once per week for five weeks prior transplanting the seedlings to pots. Common irrigation regime was applied to all the seedlings with all the tested treatments (including control) keeping the substrate humidity at $100 \%$ of the field capacity, regularly controlled with instrumental measurements (SM150 Soil Moisture Kit). One month and half later

Table 1. Treatment regime for biostimulant application in containerized Eucalyptus globulus seedlings

\begin{tabular}{lcc}
\hline $\begin{array}{c}\text { Application } \\
\text { method }\end{array}$ & $\begin{array}{c}\text { Treatment } \\
\text { code }\end{array}$ & $\begin{array}{c}\text { Biostimulant } \\
\text { concentration }\end{array}$ \\
\hline Control & CTR & 0 \\
Soil drench & S10 & $10 \mathrm{ml} / 1$ \\
Soil drench & S20 & $20 \mathrm{ml} / 1$ \\
Foliar application & F2.5 & $2.5 \mathrm{ml} / 1$ \\
Foliar application & F5.0 & $5.0 \mathrm{ml} / 1$ \\
\hline
\end{tabular}


(i.e. 45 days), seedlings were transplanted in a 10 litres pots with sand as substrate and $\mathrm{pH}$ around 7.5. Maintenance fertilization was performed by adding 20 grams of Agroblen 9-20-8+3MgO+0.2B, a fully coated, NPK with Boron, controlled-release fertilizer, designed for medium to long-term crops. Pots were placed directly on the ground using a fully randomized block scheme spatial layout with 30 seedlings per treatments. Drip irrigation was applied continuously with the same rules above mentioned (i.e. $100 \%$ of soil capacity).

\section{Growth measurements and statistical analysis}

Measurements were performed 120 days after transplanting. For each seedling the total height (HT), collar diameter (CD) and number of apical shoots (ASN) were measured/counted. Then dry biomass was measured with the total dry biomass (DB) calculated as the sum of the weights (in grams) of each part. All the seedlings were oven-dried at $105^{\circ} \mathrm{C}$ and the final dry weight in grams was obtained with repeated measurements over the same samplings until three stable measures were collected. The dry biomass of the stem (DBS), of the leaves (DBL), of the roots (DBR) were the elementary measurements we made. Then and similarly to $\mathrm{DB}$, the dry biomass above the ground (DBA) was derived as the sum of DBL and DBS. Data were analysed under a one-way ANOVA to test whether any statistical difference was detectable. A data screening was done prior analysis to test whether assumptions of parametric analysis were satisfied using the Kolmogorov-Smirnov tests for normality of the distribution and Bartlett test for homogeneity of variances. Differences among treatment means were then separated by means the post-hoc test at the $\mathrm{p}<0.05$ level of probability. In this study the multiple comparisons of treatments by means of least significant difference with adjusted p-values and a grouping of treatments was used (Steel et al., 1997). Finally, a contrasts analysis was performed to test whether the biostimulant application was able to influence growth in general and despite the application method. Contrasts were evaluated according to the following equation:

$$
C_{i}=\frac{1}{4} M_{s 10, i}+\frac{1}{4} M_{s 20, i}+\frac{1}{4} M_{F 2.5, i}+\frac{1}{4} M_{F 5.0, i}-1 M_{C T R, i}
$$

where $M_{x i}$ is the arithmetic mean of the treatment $x$ or control (CTR) for the measured $i$ growth parameter. Confidence intervals were also computed using a $95 \%$ confidence interval.

\section{Results}

No issues related to application of biostimulant on survival were reported and the variability of the collected data across all treatments including the control is summarized in Table 2 . With a coefficient of variation (CV) of $60.68 \%$ and $57.08 \%$, the variability was highest for ASN and dry DBR respectively. Conversely, the most uniform parameter was $C D$ with a CV below 20\% (19.54\%). Except for DBR and ASN, for which the relationship was not statistically significant, all other the measured growth parameters were highly correlated with each other and characterized by p-values often lower than 0.01 (Table 3 ).

All the measured data were respecting the assumptions of parametric analysis and the statistical analysis of the data revealed that the biostimulant effect was not significant for all growth parameters and treatments we measured. While none of the treatments had a statistically significant impact on HT, a general trend was notable with F2.5, F5.0 and S10 showing higher mean values than S20 and the control. Likewise, none of the performed treatments had a significant effect on CD. The application of biostimulant further failed to increase the below ground biomass, expressed by DBR and without any indication on the application method and concentration we used (Fig. 1). Conversely, the aboveground biomass (DBA) was increased significantly for all four tested treatments with foliar application at 2.5 $\mathrm{ml} . \mathrm{l}^{-1}$ resulting in double increase in biomass (Fig.

Table 2. Summary statistics of all the measured seedlings after transplanting

\begin{tabular}{lccccrrrr}
\hline & HT & CD & ASN & DBS & DBL & DBA & DBR & DB \\
\hline Min & 38.00 & 4.12 & 0.00 & 1.28 & 3.32 & 4.82 & 1.19 & 6.09 \\
Q1 & 45.00 & 4.79 & 4.00 & 3.79 & 8.35 & 12.31 & 3.53 & 17.57 \\
Median & 50.00 & 5.27 & 6.00 & 5.48 & 10.92 & 16.61 & 5.98 & 22.41 \\
Mean & 54.30 & 5.68 & 6.19 & 5.49 & 10.64 & 16.13 & 6.22 & 22.35 \\
Q3 & 64.50 & 6.66 & 9.17 & 6.76 & 12.80 & 19.99 & 7.13 & 25.66 \\
Max & 80.00 & 8.15 & 12.00 & 11.74 & 20.15 & 30.96 & 16.61 & 47.49 \\
St. Dev. & 11.58 & 1.11 & 3.75 & 2.39 & 4.01 & 6.23 & 3.55 & 8.80 \\
CV & $21.33 \%$ & $19.54 \%$ & $60.68 \%$ & $43.48 \%$ & $37.66 \%$ & $38.62 \%$ & $57.08 \%$ & $39.37 \%$ \\
\hline
\end{tabular}

HT - Total height of the seedling; CD - Collar Diamater; ASN - Apical Shoots Number; DBS - Dry Biomass of the Stem; DBL - Dry Biomass of Leaves; DBA - Dry Biomass Above the ground; DBR - Dry Biomass of Roots; DB - total Dry Biomass. 
Table 3. Correlation matrix (Spearman) between measured growth parameters

\begin{tabular}{|c|c|c|c|c|c|c|c|c|}
\hline & $\mathrm{HT}$ & $\mathrm{CD}$ & ASN & DBS & DBL & DBA & DBR & $\mathrm{DB}$ \\
\hline HT & 1 & & & & & & & \\
\hline $\mathrm{CD}$ & $1.00^{* * *}$ & 1 & & & & & & \\
\hline ASN & $0.47^{* *}$ & $0.47^{* *}$ & 1 & & & & & \\
\hline DBS & $0.74^{* * *}$ & $0.74^{* * *}$ & $0.45^{* *}$ & 1 & & & & \\
\hline DBL & $0.81^{* * *}$ & $0.81^{* * *}$ & $0.62^{* * *}$ & $0.84^{* * *}$ & 1 & & & \\
\hline DBA & $0.80^{* * *}$ & $0.80^{* * *}$ & $0.56^{* * *}$ & $0.93^{* * *}$ & $0.97^{* * *}$ & 1 & & \\
\hline DBR & $0.59^{* * *}$ & $0.59 * * *$ & 0.08 & $0.53^{* *}$ & $0.54^{* * *}$ & $0.55^{* * *}$ & 1 & \\
\hline DB & $0.81^{* * *}$ & $0.81^{* * *}$ & $0.47^{* *}$ & $0.88^{* * *}$ & $0.92^{* * *}$ & $0.95^{* * *}$ & $0.76^{* * *}$ & 1 \\
\hline
\end{tabular}

HT - Total height of the seedling; CD - Collar Diamater; ASN - Apical Shoots Number; DBS - Dry Biomass of the Stem; DBL - Dry Biomass of Leaves; DBA - Dry Biomass Above the ground; DBR - Dry Biomass of Roots; DB - total Dry Biomass. Statistically significant correlation values were reported with asterisks according to the following rule: ${ }^{* * *}-\mathrm{p} \leq 0.001 ;{ }^{* *}-\mathrm{p} \leq 0.01 ;^{*}-\mathrm{p} \leq 0.05$.
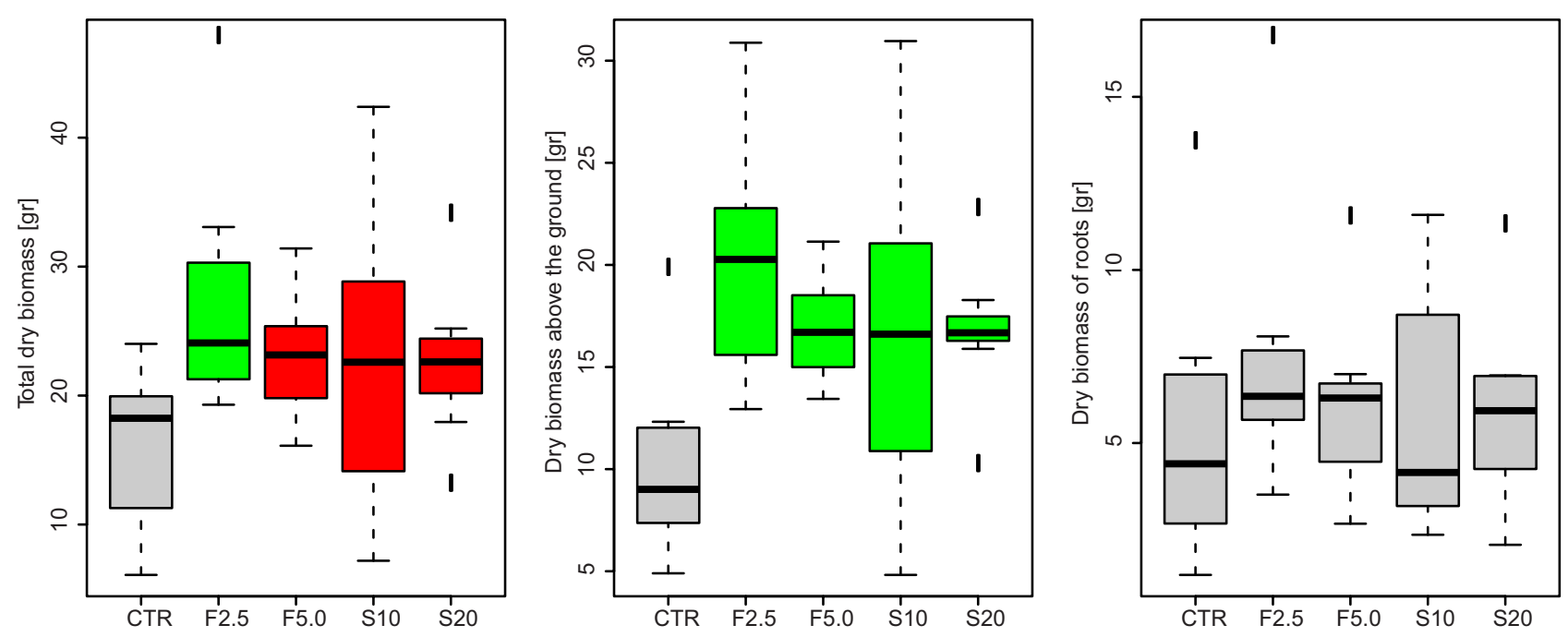

Fig. 1. Total dry biomass (DB, left), dry biomass of roots (DBR, centre) and above ground biomass (DBA, right) of containerized Eucalyptus seedlings as a function a biostimulant treatment determined at day 120 after transplanting. Boxplots are coloured according to the statistical groups detected by the post-hoc test: grey $=b$, red $=a b$, green $=a$
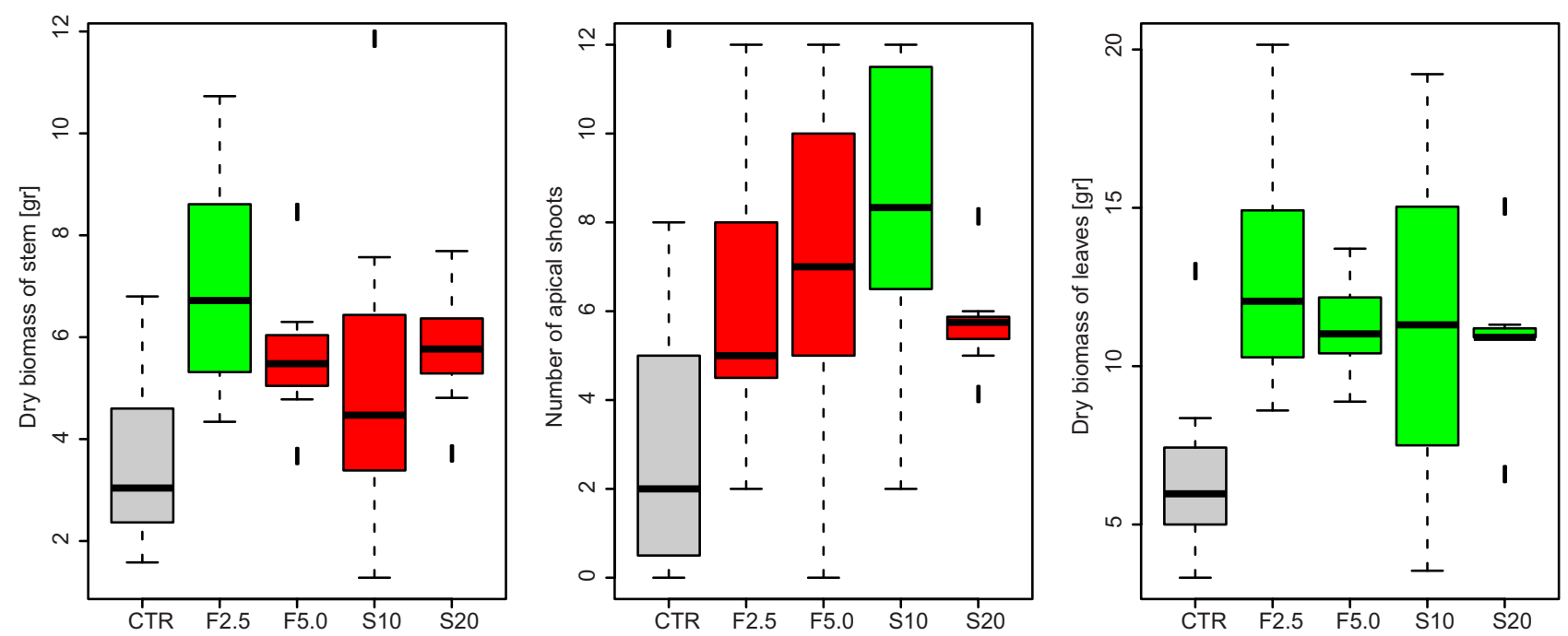

Fig. 2. Dry biomass of the stem (DBS, left), apical shoots number (ASN, centre) and total dry biomass of leaf (DBL, right) of containerized Eucalyptus seedlings as a function a biostimulant treatment determined at day 120 after transplanting. Boxplots are coloured according to the statistical groups detected by the post-hoc test: grey $=b$, red $=a b$, green $=a$ 
Table 4. Contrasts analysis and confidence intervals of measured parameters. When zero is included within upper and lower intervals (e.g. HT), the effect of biostimulant application can't be assumed as influencing the parameter(s) significantly

\begin{tabular}{lccr}
\hline $\begin{array}{c}\text { Growth } \\
\text { parameter }\end{array}$ & Estimate & $\begin{array}{c}\text { Lower } \\
\text { estimate }\end{array}$ & $\begin{array}{c}\text { Upper } \\
\text { estimate }\end{array}$ \\
\hline HT & 8.0595 & -1.6774 & 17.7964 \\
CD & 0.7729 & -0.1609 & 1.7067 \\
ASN & 3.2708 & 0.1457 & 6.3959 \\
DBS & 2.3317 & 0.3995 & 4.2639 \\
DBL & 4.9152 & 1.7964 & 8.0340 \\
DBA & 7.2469 & 2.3539 & 12.1398 \\
DBR & 0.9074 & -2.2876 & 4.1024 \\
DB & 8.1543 & 0.8822 & 15.4263 \\
\hline
\end{tabular}

HT - Total height of the seedling; CD - Collar Diamater; ASN - Apical Shoots Number; DBS - Dry Biomass of the Stem; DBL - Dry Biomass of Leaves; DBA - Dry Biomass Above the ground; DBR - Dry Biomass of Roots; DB - total Dry Biomass.

2). The foliar application at $2.5 \mathrm{ml} . \mathrm{l}^{-1}$ was also the only statistically significant treatment affecting the total biomass accumulation (DB). Numeric average values for the measured parameters are available in the supplementary material (Table S1).

The influence of the biostimulant on DBA becomes further apparent by decomposing the effect on the individual parts of the plant. When separated as DBS, ASN and DBL, the results demonstrated that the biostimulant had effect on the above ground biomass allocation by creating more shoots and consequently more DBL. While leaves biomass was increased significantly across all treatments when compared to control, the effect was significant for foliar application at $2.5 \mathrm{ml} \cdot \cdot^{-1}$ and soil at $10 \mathrm{ml} \cdot \cdot^{-1}$ for DBS and ASN, respectively. Despite the significant effect of the biostimulant application on biomass accumulation and expressed by difference of the DB, DBS, DBA, DBL and ASN, the within-treatments variances were too low to support any significant effect of application method (soil versus foliar). Further, the within-treatment effect of the concentration, $2.5 \mathrm{ml} . \mathrm{l}^{-1}$ versus $5.0 \mathrm{ml} . \mathrm{l}^{-1}$ and $10.0 \mathrm{ml} . \mathrm{l}^{-1}$ versus $20.0 \mathrm{ml} . \mathrm{l}^{-1}$ for foliar and soil drench application respectively were not different from each other.

Finally, the contrasts analysis showed that higher performances were obtained with biostimulants for all the measured parameters except HT, CD and DBR. Indeed, these three parameters were the only whose interval included the zero (Table 4).

\section{Discussion}

The increased aboveground biomass was one of the main impacts of Siapton ${ }^{\circledR}$ biostimulant on $\mathrm{Eu}$ calyptus globulus seedlings after transplanting and in agreement with the results from previous studies for selected agricultural plants and fruit trees (Grabowska et al., 2013; Subbarao et al., 2015). An accumulation of DB mainly in the stem can suggest a higher growth rate due to more leaves. No effect was detectable for roots, which could be a strategy to reduce drought risks in a changing environment. The ability of biostimulant to minimize the effects of abiotic stress has been discussed in literature (Van Oosten et al., 2017) and can be acknowledged as the main result of this study. Neither foliar nor soil drench application influenced the belowground biomass accumulation and contrary to the effect on the aboveground biomass. This is surprising especially for soil drench application, where an effect was expected in some way, and in contradiction to other studies, where root growth and development was increased following biostimulant treatment (Colla et al., 2014). However, the result is comprehensible, considering the mechanism of Siapton ${ }^{\circledR}$, shown to improve uptake and utilization of nitrogen by activating the enzyme systems GDH-NAD and NR as described in (Mladenova, 1978).

The main effect from the treatment is the increase apical shoot and consequently a more important leaves formation. Unfortunately, the lack of comparable literature data on the influence of animal derived protein hydrolysate on Eucalyptus spp. growth doesn't enables a direct and clear verification of the results. In addition, the post-transplanting growth response mechanism discussed in this study is essentially different to the immediate growth response following direct application as referred to in most literature studies (e.g. Cristiano et al., 2018; Fraser \& Percival, 2003). An enhancement of stress tolerance in general, and the reduction of transplanting stress, as an effect of preconditioning biostimulant treatment might be the main explanation for the increased growth of the treated seedlings following transplanting.

While the influence from the treatment on aboveground biomass accumulation is obvious, no effect from application method and concentration was reported. The statistical analysis between soil drench and foliar application at different concentrations does not support any significant differences. However, the positive trend that highlights the benefits of foliar as opposed to soil drench application was interesting and worth to be further investigated. Lower inputs (i.e. biostimulant quantity) was also necessary for foliar than for soil drench application. the effective rate to be used in commercial application needs to be verified. Further, application frequency and timing before transplanting to field should be a focus of investigations. Long-term effect on growth exceeding the 120 days as tested in this study will be necessary to draw valid conclusions regarding the real application benefits. 


\section{Conclusions}

Understanding of the role of biostimulant action on nitrogen uptake and use efficiency by the plant could be focal to assess their potential benefits about sustainable use of fertilization, especially during nursery activities. The biostimulant treatment on containerized Eucalyptus globulus positively influenced some features of seedlings' growth after transplanting and the use of biostimulant with foliar application during the hardening phase in the nursery, appears to be a promising technique to potentially improve seedling growth after transplanting. Potential application of biostimulant during the hardening phase in the nursery using foliar or soil application methods (or both) is proposed as follow-up studies, with the expected result to increase survival rate by reducing transplanting stress and increase growth after transplanting to field.

\section{Acknowledgements}

The authors would like to express their deepest gratitude to Mr. Domenico Zocco who introduced the authors to the topic of biostimulants and supported this research.

\section{Funding}

This study was funded by Omya International AG.

\section{References}

Banks JM \& Percival GC (2014) Failure of foliar-applied biostimulants to enhance drought and salt tolerance in urban trees. Arboricolture \& Urban Forestry 40: 78-83.

Barboza Frioni F (2013) Efecto de fertilizatiojn y aplicacion de biostimulantes en el desarrollo inicial de plantaciones de Eucalyptus globulus sobre suelos de lavalleja y rocha. Dissertation. Universidad de la República, Montevideo Uruguay.

Barnes S \& Percival GC (2006) Influence of biostimulants and water-retaining polymer root dips on survival and growth of newly transplanted bare-rooted silver birch and rowan. Journal of Environmental Horticulture 24: 173-179.

Brocco Silva J, Martinez Kremer PM \& Oteguli Olguin JE (2015) Evaluación de crecimiento y sanidad en una plantación de Eucalyptus maidenii en función del agregado de fertilizantes con y sin bioestimulantes. Dissertation. Universidad de la República, Montevideo Uruguay.

Caradonia F, Battaglia V, Righi L, Pascali G \& La Torre A (2019) Plant biostimulant regulatory framework: prospects in Europe and current situation at international level. Journal of Plant Growth Regulation 38: 438-448. doi:10.1007/s00344018-9853-4.

Colla G, Rouphael Y, Canaguier R, Svecova E \& Cardarelli M (2014) Biostimulant action of a plant-derived protein hydrolysate produced through enzymatic hydrolysis. Frontiers in Plant Science 5: 448. doi:10.3389/fpls.2014.00448.

Colla G, Hoagland L, Ruzzi M, Cardarelli M, Bonini P, Canaguier R \& Rouphael Y (2017) Biostimulant action of protein hydrolysates: unraveling their effects on plant physiology and microbiome. Frontiers in Plant Science 8: 1-14. doi.org/10.3389/ fpls.2017.02202.

Coyle DR \& Coleman MD (2005) Forest production responses to irrigation and fertilization are not explained by shifts in allocation. Forest Ecology and Management 208: 137-152.

Cristiano G, Pallozzi E, Conversa G, Tufarelli V \& De Lucia B (2018) Effects of an animal-derived biostimulant on the growth and physiological parameters of potted snapdragon (Antirrhinum majus L.). Front Frontiers in Plant Science 9: 861. doi:10.3389/fpls.2018.00861.

de Pascale S, Rouphael Y \& Colla G (2017) Plant biostimulants: innovative tool for enhancing plant nutrition in organic farming. European Journal of Horticultural Science 82: 277-285. doi:10.17660/ eJHS.2017/82.6.2.

du Jardin P (2015) Plant biostimulants: Definition, concept, main categories and regulation. Scientia Horticulturae 196: 3-14. doi:10.1016/j.scienta.2015.09.021.

Filiti N, Cristoferi G \& Maini P (1986) Effects of biostimulants on fruit trees. Acta Horticulture 179: 277-278. doi:10.17660/ActaHortic.1986.179.36.

Fraser GA \& Percival GC (2003) The influence of biostimulants on growth and vitality of three urban tree species following transplanting. Arboricultural Journal 27: 43-57. doi:10.1080/03071375. 2003.9747361.

Grabowska A, Kunicki E, Sękara A, Kalisz A \& Wojciechowska R (2013) The effect of cultivar and biostimulant treatment on the carrot yield and its quality. Vegetation Crop Research Bulletin 77: 37-48. doi:10.2478/v10032-012-0014-1.

Hall AJ \& Richards RA (2013) Prognosis for genetic improvement of yield potential and water-limited yield of major grain crops. Field Crops Research 143: 18-33. doi:10.1016/j.fcr.2012.05.014.

Halpern M, Bar-Tal A, Ofek M, Minz D, Muller T \& Yermiyahu U (2015) Chapter two - the use of biostimulants for enhancing nutrient uptake. Advances in Agronomy 130: 141-174. doi:10.1016/ bs.agron.2014.10.001.

Kaufmann GL, Kneivel DP \& Watschke TL (2007) Effects of a biostimulant on the heat tolerance 
associated with photosynthetic capacity, membrane thermostability, and polyphenol production of perennial ryegrass. Crop Science 47: 261-267. doi:10.2135/cropsci2006.03.0171.

Le Mire G, Nguyen M, Fassotte B, du Jardin P, Verheggen F, Delaplace P \& Jijakli H (2016) Review: Implementing biostimulants and biocontrol strategies in the agroecological management of cultivated ecosystems. Biotechnologie, Agronomie, Société et Environnement 20 (S1): 299-313. http://hdl.handle.net/2268/188662.

Lucini L, Rouphael Y, Cardarelli M, Canaguier R, Kumar P \& Colla G (2015) The effect of a plant-derived biostimulant on metabolic profiling and crop performance of lettuce grown under saline conditions. Scientia in Horticulturae 182: 124 133. doi:10.1016/j.scienta.2014.11.022.

Mladenova YI (1978) Effect of L-glutamic acid and Siapton leaf organic fertilizer on oxidized nicotinamide adenine dinucleotide dependent glutamate dehydrogenase of different maize genotypes. Journal of Agriculture and Food Chemistry 1978 26: 1274-1276. doi:10.1021/jf60220a034.

Mladenova YI, Maini P, Mallegni C, Goltsev V, Vladova R, Vinarova K \& Rotcheva S (1998) Siapton - an amino-acid-based biostimulant reducing osmostress metabolic changes in Maize. Agro Food Industry Hi-Tech 9: 18-22.

Moroy Rodriguez GJ \& Sanchez Giménez FL (2017) Evaluacion de manejo de biostimulante en pos plantacion de Eucalyptus globulus spp. Globulus. Dissertation. Universidad de la República, Montevideo Uruguay.

Perry C, Steduto P, Allen RG \& Burt CM (2009) Increasing productivity in irrigated agriculture: Agronomic constraints and hydrological realities. Agriculture and Water Management 96: 15171524. doi:10.1016/j.agwat.2009.05.005.

Richardson AD, Aikens M, Berlyn GP \& Marshall P (2004) Drought stress and paper birch (Betula papyrifera) seedlings: Effects of an organic biostim- ulant on plant health and stress tolerance, and detection of stress effects with instrument-based, noninvasive methods. Journal of Arboriculture 30: 52-60.

Steel RGD, Torrie J \& Dickey D (1997) Principles and procedures of statistics: A biometrical approach. 3rd ed. McGraw-Hill, New York, NY.

Subbarao SB, Aftab Hussain IS \& Ganesh PT (2015) Bio stimulant activity of protein hydrolysate: Influence on plant growth and yield. Journal of Plant Science and Research 2: 125

Van Oosten MJ, Pepe O, De Pascale S, Silletti S \& Maggio A (2017) The role of biostimulants and bioeffectors as alleviators of abiotic stress in crop plants. Chemical and Biological Technologies in Agriculture 4: 5. doi:10.1186/s40538-017-00895.

Wagner RG, Little KM, Richardson B \& Mcnabb K (2006) The role of vegetation management for enhancing productivity of the world's forests. Forestry: An International Journal of Forest Research 79: 57-79. doi:10.1093/forestry/cpi057.

Wang X \& Xing Y (2017) Evaluation of the effects of irrigation and fertilization on tomato fruit yield and quality: a principal component analysis. Scientific Reports 7: 350. doi:10.1038/s41598-01700373-8.

Xu C \& Leskovar DI (2015) Effects of A. nodosum seaweed extracts on spinach growth, physiology and nutrition value under drought stress. Scientia Horticulturae 183: 39-47.

Yakhin OI, Lubyanov AA, Yakhin IA \& Brown PH (2017) Biostimulants in plant science: A global perspective. Frontiers in Plant Science 7: 2049. doi:10.3389/fpls.2016.02049.

Zhu K, Zhou H \& Qian H (2006) Antioxidant and free radical-scavenging activities of wheat germ protein hydrolysates (WGPH) prepared with alcalase. Process Biochemistry 41: 1296-1302. 